\title{
El yo desnudo. La puesta en escena del yo en la obra de Liliana Maresca
}

Valeria Stefanini *

Resumo: Este texto reflexiona sobre dos obras de la artista argentina Liliana Maresca: Espacio disponible y Maresca se ofrece todo destino, tratando de establecer las líneas que unen las dos muestras, y observar cómo se complementan para alcanzar un objetivo que podemos rastrear en prácticamente todas sus obras: establecer un dialogo con el espectador e influir en su vida de alguna manera, generar una reflexión propia y hacer pensar al otro. Las dos obras elegidas serán pensadas desde marcos teóricos de la semiología y del análisis del discurso para poder abarcar la complejidad que ambas proponen en la indagación acerca del rol del artista en el medio local, del uso del cuerpo y su puesta en escena, y los vínculos que el artista mantiene con las instituciones y el mercado.

Basaremos este trabajo en la información obtenida en entrevistas, para poder dar cuenta de la palabra de la propia artista que quedó registrada y grabada por distintas personas en el transcurso de su carrera.

Palabras claves: Liliana Maresca - Arte contemporáneo - Semiología - Cuerpo - Análisis del discurso - Fotografía - Arte argentino.

[Resúmenes en inglés y portugués en la página 254]

${ }^{(*)}$ Valeria Stefanini es licenciada en Artes por la Universidad de Buenos Aires y la Universidad de Chile, con un posgrado en Gestión Cultural por la Universidad de Chile, actualmente está realizando la Maestría en Sociología de la Cultura y Análisis Cultural en la Universidad Nacional de San Martín. Sus áreas de interés e investigación son: temas que vinculan la ética y la fotografía, estudios sobre el uso del cuerpo en las artes plásticas y la fotografía, relaciones entre estudios de género y la representación del cuerpo y la fotografía de moda. Es docente de historia del arte y ética en distintas universidades y escuelas de arte, diseño y fotografía, coordina grupos de estudio sobre historia del arte. Forma parte desde 2016 del grupo de investigación sobre Arte y Fotografía contemporánea radicado en UADE. Integra el cuerpo docente de la Facultad de Diseño y Comunicación de la Universidad de Palermo.

\section{¿Y la obra? ¿Dónde está la obra?}

El final del siglo XX ha hecho evidente que el problema del arte surge desde el principio, desde la reflexión sobre el propio objeto de estudio. 
Desde el momento en que tratamos de pensar la obra y la situamos en un marco de referencia que la vincula con otras obras que sabemos que existen y sobre las que sí hay acuerdo en la historia del arte, enfrentamos un problema que es pensar la obra contemporánea con categorías de obras decimonónicas. Entonces la pregunta, ¿dónde está la obra? ¿cuál es esa obra?, se vuelve importante y significativa. Es probable que la manera de esclarecer esto sea entender que la respuesta gira en torno a la búsqueda de los marcos teóricos que nos van a permitir y facilitar pensar la obra.

En este trabajo se pretende realizar una indagación acerca de dos obras de la artista argentina Liliana Maresca. La primera: Espacio Disponible que fue montada en diciembre de 1992 en el Casal de Catalunya en vinculación y relación con una obra un poco posterior, Maresca se entrega todo destino, una serie de 14 fotografías realizadas un año después, en 1993 que fueron publicadas en la revista erótica El Libertino.

El corpus fue elegido entre toda la producción de la artista ya que son dos obras que pueden pensarse en relación y se complementan y que, cada una con sus propias estrategias, se refieren a temas en común. Las dos obras hablan acerca del rol de la artista en el arte contemporáneo en la década del 90 en Buenos Aires, un tema que sigue siendo vigente y significativo más de 20 años después.

En general la obra de Maresca predispone a una profunda reflexión teórica, es una obra que abre múltiples líneas de pensamiento acerca de temas tan complejos como la sexualidad, la libertad, la historia, la política, el arte y el/la artista, el mercado del arte y su exhibición, distribución y circulación, la desigualdad y la pobreza, la ciudad y la alienación entre muchos otros temas fundamentales que podríamos empezar a reconocer trabajados en gran parte de sus obras. En todas estas la artista pone el cuerpo para hacer propios los temas que le interesan, participa, se muestra, se exhibe, se presenta. La elección particular de estas dos obras responde a que permiten pensar acerca de la estrategia como procedimiento de la producción artística de Maresca. Son dos obras que elaboran un tema similar de dos maneras diferentes y ella misma las vincula y compara para pensar el resultado. Quizá podríamos llegar a pensar que si la obra Espacio Disponible hubiera generado la respuesta que la artista buscaba la otra obra Maresca se entrega todo destino no hubiera sido necesaria. La propia artista habló varias veces en relación a estas dos obras, en este caso Julio Sánchez recupera sus palabras,

Esa fue una muestra (refiriéndose a la obra Espacio Disponible en el Casal de Catalunya) para un grupo reducido de artistas plásticos y que no tenía nada de erótico, era puramente intelectual, casi nadie la entendió y hubo gente que me preguntaba dónde estaba la muestra. En cambio, en la muestra de El Libertino el erotismo funciona como comunicación básica, y por eso la gente se engancha con esta obra; en la primera muestra no me llamó nadie, pero en esta última tengo un promedio de cinco llamadas telefónicas diarias.

Desde esta hipótesis el análisis se construirá enlazando estas dos obras que nos permitirán comprender un punto de vista sólido y profundo acerca del rol de la artista, especialmente de la artista mujer, inmersa en la sociedad contemporánea y en el mercado del arte. 
Hemos trabajado la obra de Maresca en investigaciones anteriores, atraídas por el modo en que la artista se presenta como protagonista de cada una de ellas y el uso de su cuerpo como elemento principal a la hora de trabajar la imagen. La artista está presente, siempre presente en cada una de sus obras y desde ahí es que la pensamos en los anteriores trabajos. Su obra fue pensada como performance y como autorretrato y desde esas dos estrategias de análisis la obra se abrió rica en sentidos y de algún modo la obra dialogó. Curiosamente en los análisis, críticas y estudios sobre las obras de Maresca el verbo hablar aparece siempre, Liliana Maresca dice, habla, enuncia desde el pasado cosas que nos siguen interesando o preocupando en el presente y es desde la repetición de este abordaje desde donde surge la inicial curiosidad que dará origen a este texto.

El objetivo que nos mueve en este momento es pensar las estrategias discursivas que desarrolla Maresca especialmente en estas dos obras elegidas como corpus y pensar las obras como discursos tomando en cuenta marcos teóricos de la semiología y del análisis del discurso.

En el Catálogo de la artista, realizado por el Museo de Arte Moderno de Buenos Aires en el año 2016, Victoria Noorthoorn ya desde la introducción dice lo siguiente:

...Maresca se interesó por el discurso, la elocuencia y la situación de enunciación. Era tan importante la obra como la situación social y discursiva del artista comunicando un estado del mundo y una visión a futuro. Su conciencia sobre el lugar del artista en la sociedad dio a su figura una relevancia fundamental que impactó enormemente en su propia comunidad artística, que a mediados de los años 80 ensayaba formas de hablar, de decir y de crear tanto arte como comunidad (p.31).

\section{Contar las obras}

Liliana Maresca es una artista que toma relevancia en la escena local en el retorno a la democracia, un momento en el que en Buenos Aires los circuitos culturales crecen enfervorizados con la promesa de libertad de expresión y de acción artística.

Su corta carrera atravesada por la enfermedad y la temprana muerte, ocurrida en 1994 con tan solo 43 años de edad, va a tocar los temas más importantes y angustiantes para su generación y que no han perdido relevancia en la actualidad. Su obra es profundamente política y establece un punto de vista acerca del cuerpo individual y social inscripto en la historia, el cuerpo atravesado por el género, por el sexo y el disfrute, el cuerpo que goza, duele y es bello, el cuerpo que es artista y es obra al mismo tiempo, el cuerpo que busca y desea ser libre en un momento en que la libertad era una esperanza que la sociedad argentina no sabía de qué manera concretar.

Liliana Maresca enferma y muere de SIDA en 1994, una enfermedad que signó la década del noventa y afecto los modos de relacionarse y los vínculos que empezaban a definirse en ese momento. Las ansias de libertad de toda una generación, que celebró los cambios políticos y sociales de 1983 con el retorno a la democracia, en los noventa se trastocan una vez más encontrando en la enfermedad un nuevo límite y una nueva restricción. 
Maresca se plantea como una artista colectiva, en muchas de sus obras contó con la ayuda de fotógrafos que realizaron las fotos de sus performances, ya sea a modo de obra o de registro de carácter documental. Alejandro Kuropatwa, Marcos Lopéz o Adriana Miranda, son las figuras siempre presentes. Maresca impone un modo de trabajo que no es común en la escena local, la colaboración y el trabajo colectivo ya que prácticamente todas sus obras cuentan con el otro, lo requieren y lo necesitan para tomar forma y poder ser. Más allá del concepto romántico del artista solitario y atormentado, Maresca hace de la obra una fiesta con muchos invitados. Ella coordina, convoca, nuclea y da sentido en una obra en la que todos son necesarios.

Un claro ejemplo de esto es cuando junto con Ezequiel Furgiuele fundó el Grupo Haga. Javier Villa en el Catálogo de la artista deja que ella lo explique con sus propias palabras, "El Grupo Haga producía eventos, producía cosas fuera de contexto, fuera de lugar... Producir, producir, producir" (p. 50) de aquí surgieron varias obras en colaboración como por ejemplo Una bufanda para la ciudad de 1985, donde los dos artistas entrelazan telas diversas y construyen una especie de recorrido textil que emergía desde la galería Adriana Indik por las ventanas hacia la calle con el lema "ahora viene el frío y hay que cuidar la salud de la ciudad", o la obra que transcurre en un lavadero, titulada Lavarte del mismo año. Todas estas estrategias buscaban sacar la obra de los museos, galerías e instituciones artísticas a la calle donde podían ser vistas por aquella gente que justamente no frecuentaba los espacios considerados tradicionalmente como espacios culturales. Los artistas que organizan Lavarte (Liliana Maresca, Ezequiel Furgiuele, Alejandro Dardik, Marcos López y Martín Kovensky) publican un texto cuando deben levantar la muestra en el que relevan su importancia, el texto menciona que “... esta experiencia ha permitido que actividades sociales y culturales que inexplicablemente continúan siendo presentadas en ambientes de élite confluyan hacia espacios no tradicionales". La galería y el museo son entendidos como espacios cerrados y restringidos a pequeños grupos en dónde se presentan obras que no se vinculan con el gran público masivo dado que este no accede, la gente común no es uno más de los invitados.

Es entonces que sacar la obra de esos lugares limitados y cerrados se vuelve una tarea fundamental. La artista sigue diciendo en el texto de Julio Sánchez,

Un entusiasmo maravilloso, porque por fin nos habíamos sacado de encima a la dictadura. Y entonces adónde íbamos, íbamos a conquistar el mundo [...] Le íbamos a devolver a la gente la confianza en el arte, que era maravilloso, que el arte podía cambiar el mundo (p. 15).

El arte es pensado para toda la gente ya que este genera una marca en la vida misma, no es creado para decorar el ambiente burgués, para embellecer o dar prestigio a espacios o personas, la labor del artista es incidir efectivamente en el mundo y en la sociedad por medio de la propia obra que crea. Con respecto a este punto ella misma menciona al hablar de su obra Maresca se entrega todo destino que,

...el arte metido en museos, años después de haberse generado no tiene validez, se convierte en un esqueleto y pierde el sentido que lo generó; si la obra 
genera algo es solamente en su contemporaneidad, el hecho de que mi muestra esté en una revista tiene que ver con nuestro medio, con la Argentina y con dos tipos que dirigen la revista que son porteños y que están insertos en el mundo de la plástica.

En general esa obra que Maresca crea está atravesada por esta intensión política y social del arte que la vuelve un instrumento para pensar y para modificar la realidad. De ahí la utilización del propio cuerpo como recurso expresivo. Gran parte de su trabajo son acciones que realiza ella misma y a las que accedemos por medio de un registro fotográfico que esta concebido como parte medular e indisociable de la obra, con fotos sacadas por fotógrafos amigos. La obra, la acción, la intención, el tiempo todo esto se funde para conformar una obra que en algunos casos desapareció ni bien fue sucediendo y de la que queda cierto recuerdo y algunos registros aislados.

La Kermese es quizá la obra colaborativa más importante de su trayectoria, en la que participan casi 200 artistas en distintas prácticas para la organización de una gran fiesta de carácter popular en el Centro Cultural Ciudad de Buenos Aires ubicado en el barrio de Recoleta, un evento efímero y convocante que se transformó en un hito del arte argentino de los 80 . El concepto de kermese remite a un evento de carácter barrial y popular en el que se realizan distintos juegos, bailes y actividades con el fin de recaudar dinero para financiar instituciones como clubes, colegios, etc., pero al realizar esta kermese en un barrio como el de Recoleta, que está ubicado en una de las zonas más elegantes de la ciudad, lo elitista y lo popular parecen juntarse por un momento en el desarrollo de la fiesta, los públicos y las actividades coinciden en un espacio de unión y celebración. La operación se invierte y en vez de sacar la obra a la calle para que interpele al espectador, lleva una obra popular a una institución artística para que dialogue con otro tipo de espectador. En los dos casos la obra sorprende a un público que no la espera o por lo menos no espera que se desarrolle de este modo.

Las dos obras que mueven esta investigación son Espacio disponible y Maresca se ofrece todo destino. En estas dos obras Maresca busca indagar acerca de la condición de la artista en el arte contemporáneo más especialmente trabaja alrededor de la problemática del mercado del arte y los condicionamientos que este impone al artista.

\section{Espacio disponible}

Esta obra se propone como una instalación en la que la artista utiliza una pequeña habitación del Casal de Catalunya en la que cuelga tres carteles que por su diseño, texto y tipografía imitan los carteles que cuelgan las inmobiliarias en los inmuebles en venta o alquiler. Dos de los carteles colgaban de las paredes con los siguientes textos escritos en concretas letras negras sobre fondo blanco: DISPONIBLE 23-5457 y ESPACIO DISPONIBLE, el tercer cartel se ubicaba en el suelo en el medio de la sala abierto de forma triangular a modo de un caballete con un texto más largo y concreto en el que se volvía a mencionar el número de teléfono pero esta vez ya se le explicaba al espectador que el espacio estaba disponible y que era apto para todo destino, también aparecía el nombre de la artista, su propio número de teléfono y por último una serie de números que hacían referencia a 
las fechas de apertura y cierre de la exposición: "ESPACIO DISPONIBLE. APTO TODO DESTINO. LILIANA MARESCA. 23-5457. DEL 3-12 AL 24-12-92".

¿Cuál era el espacio que Maresca publicitaba como disponible?

Por un lado hay un espacio físico concreto que es el de la galería y esos carteles colgados podían referir a que hasta durante la misma muestra en el espacio no había nada, nada más que el anuncio de que ahí no había nada y que por consiguiente eso estaba disponible para lo que lo quisieran usar, entonces podríamos pensar que esta instalación proponía una reflexión dentro del ámbito del arte y alrededor de la obra. Si este era el mensaje es significativo que nadie intervino el espacio de ninguna manera.

$\mathrm{Si}$, en cambio, lo que estaba disponible era un lugar simbólico en el medio artístico, quizá con su anuncio Maresca estaba preanunciando su propia muerte o las derivas que atravesarían el arte contemporáneo hasta el día de hoy en el que la acción colectiva y política del arte, su espíritu revolucionario es cada vez más difuso, si la intensión era marcar eso para que alguien asuma el desafío de continuar con el reto, tampoco esto fue comprendido y no propicio ninguna acción en consecuencia.

El texto de la muestra incluía un fragmento de Chiang Tzu, filósofo chino del siglo IV aC., que finalizaba diciendo: "Vaciaré yo también mi voluntad para andar sin rumbo alguno, ignorante de mi paradero. Iré y volveré sin saber dónde me voy a detener. Iré y vendré ignorante del término de mis andanzas. Erraré por espacios inmensos". De alguna manera más allá de todos los sentidos posibles que podamos encontrarle a esta instalación y de todas las reflexiones que nos proponga, es inevitable que en la relación con el texto y especialmente con esta frase no sospechemos que algo del espacio que se abre es el que preanuncia la partida de la propia artista.

El texto que acompañaba la muestra aparecía publicado en una hoja de exposición escrito por Fabián Lebenglik. Ya desde el título parece querer indicarnos con claridad una intensión posible de la obra/instalación/muestra/acción. Lebenglik titula su breve texto: Maresca se vende. En función de esto parece ser claro que es la condición de la artista y su relación con el mercado del arte lo que está en juego en esta obra en la que ella se coloca en el mismo lugar simbólico del espacio y se ofrece a todo destino igual que la habitación vacía. Más allá de lo que Maresca estuviese poniendo a disposición del público lo que sí es relevante es que nadie llamó al número que aparecía en dos de los tres carteles que era el número de teléfono de la propia casa de la artista. Julio Sanchez cita las palabras de la propia Maresca que nos cuenta, "Ésa fue una muestra para un grupo reducido de artistas plásticos y que no tenía nada de erótico, era puramente intelectual, casi nadie la entendió y hubo gente que me preguntaba dónde estaba la muestra" (p. 15).

\section{Maresca se entrega todo destino}

En octubre de 1993 se publica a doble página en la revista de relatos eróticos El Libertino la obra Maresca se entrega todo destino. Las fotos son parte de una propaganda a doble página que salió publicada en la revista, con una serie de catorce fotografías en blanco y negro que registran a Maresca en poses provocativas. Maresca aparece levemente vestida o casi desnuda jugando con un osito de peluche. La obra tiene un texto que le da título: Maresca se entrega todo destino, el teléfono de ella, y los créditos en los que dice los siguiente, "La escul- 
tora Liliana Maresca donó su cuerpo a Alex Kuropatwa -Fotógrafo-, Sergio De Loof-Trend Setter-, y Sergio Avello -Maquilladora- Para este maxi aviso donde se dispone a todo".

La obra resulta entonces de la acción colaborativa en la que participan distintos personajes muy conocidos en la escena artística y under local. Sergio De Loof y Sergio Avello realizaran el vestuario y maquillaje, la publicación será registrada bajo el copyright de Fabulous Nobodies, marca de Roberto Jacoby y Kiwi Sainz, y Alejandro Kuropatwa realizará la fotografía. Más de trescientas personas llamaron al número ofrecido en la publicidad. Con cuatro de las cuales la artista se reunió. Es posible que la explícita identificación de Maresca como una escultora que aparece en el texto hiciera que muchas personas notaran que no era una llamada a una línea Hot común y percibieran que la publicidad era parte de algo más, aunque no todos los usuarios de la revista se detuvieran a pensar en ello.

la gente que llamaba se enganchaba por lo erótico, salvo dos que se engancharon por lo intelectual de la obra [...] Aún hoy después de tres meses sigo recibiendo llamados, fundamentalmente establezco una comunicación telefónica, cuando alguien llama y escucha mi voz se da cuenta de que esto no es prostitución (Maresca).

¿Qué es eso erótico que "engancho" a quienes llamaron? Carlos Cuellar plantea una definición de la representación del cuerpo erótico que puede empezar a ayudarnos a pensar en lo que significa la intervención del arte en un espacio marcado por el erotismo,

... el audiovisual erótico tiene como tema principal la seducción y la relación sexual, real o ficticia de sus actantes. El género erótico y las escenas eróticas incluidas en films pertenecientes a otros géneros se caracterizan, generalmente por la mostración del cuerpo humano, fundamentalmente femenino como agente seductor y objeto pasional consumido por un público masculino o femenino. Heterosexual u homosexual, cuya pulsión escópica se identifica con la sexual.

Los argumentos salvo honrosas excepciones suelen carecer de interés y se limitan a justificar la presencia de imágenes caracterizadas por su claridad, nitidez y particular fragmentación corporal a través de numerosos primeros planos e insertos (p. 178).

La vuelta que logra dar Maresca es justamente hacer una obra en la que la presencia del factor erótico no anule el argumento sino todo lo contrario genera una lectura rica y profunda.

Maresca también va a plantearnos su propia definición de erotismo,

Creo que el erotismo es la comunicación más primaria, y yo con mi obra estoy hablando del amor, del encuentro, de la amistad con otro. Estoy rescatando la posibilidad de disfrutar de mi cuerpo, que no se hizo para sufrir sino para gozar, la obra me sirve para conectarme con mi propio erotismo, y para superar mi tilinguería (Sánchez, p.15). 
Maresca no deja al deseo sólo separado del amor y de su comunión con el otro, el erotismo es lo que me une con otro y allana el camino para permitirme dialogar.

La elección de una revista erótica es una cuestión de estrategia, que refleja un punto de vista por parte de la artista hacia el uso de su propio cuerpo. "El gesto de apertura total es un hecho artístico, desnudarse y ofrecer todo es como hacer body art (arte del cuerpo), expresar una idea con mi cuerpo". Desnudarse es un hecho artístico y el uso del cuerpo desnudo entra en el ámbito del discurso promulgado, de lo dicho.

De todos los mensajes que recibió de gente que llamó al número que aparecía publicado en la revista ella eligió sólo a cuatro y estableció una comunicación por medio de entrevistas personales, la artista reconoce que algo muy interesante que sucedió con esta obra,

... esta es la primera vez que tengo retorno con una muestra, la obra continúa con los llamados que hacen pensar qué estoy haciendo. El público es gente que está fuera del circuito de la plástica, no me llaman para decirme ‘Qué buena tu obra!': en general la captación es elemental, evidentemente cuanto más elemental, más llegás a la mayoría de la gente [...]

Maresca reconoce en esta obra la oportunidad de una apertura al dialogo con un espectador que no es un amigo o alguien del medio artístico con el que ya está establecido que se manejan los mismos códigos que nos permiten pensar las obras y sus problemas, la posibilidad de hablar con otro que real y claramente es otro permite contrastar, poner en juego y en tensión el propio discurso.

\section{Yo, tu y eso qué nos vamos diciendo}

¿Por qué pensar el arte como discurso?

Los riesgos de pensar el arte desde otro lado, desde otra disciplina que no sea la artística nos enfrenta a la angustia de perder la especificidad del arte, de transformarlo en discurso, transformarlo en política, transformarlo en movimiento social o histórico, transformarlo en propaganda. El problema de la transversalidad amenaza con hacer perder el eje que le da a la obra la posibilidad de ser catalogada como obra de arte o expulsarla por un rato o para siempre del circuito artístico. Pero hay que tener en cuenta que esto no es necesariamente lo que preocupa a Maresca, a quién quizá no le molestaba ni le importaba, sino que es el problema del teórico que si necesita para su propio quehacer definir el marco desde el que va a pensar, definir el corpus que va a analizar y establecer el campo sobre el que va a trabajar. Si pensamos que esto no es lo que le preocupa especialmente a Maresca es porque ella misma en un dialogo con Furgiuele que fue grabado en una serie de videos por Adriana Miranda en el invierno de 1993 dice,

[...] lo único que me interesa es que el ser humano pueda producir una obra que conmocione a otros, que comunique cosas, que hable, que sea revulsiva, que hable de la mierda, del horror, del querer trascender ese horror y esa mierda... (Maresca citada por Villa, p. 68). 
Es evidente que la obra contemporánea no permite un análisis formal al modo de cualquier obra del pasado, los análisis que piensan en el color, las líneas, el tratamiento del espacio, la pincelada, la capacidad mimética de representar la realidad, las texturas o que ponen el eje en un análisis pensando en el diseño, no nos sirven para pensar en una habitación blanca con tres carteles colgados impresos con un texto breve o en una serie de fotos montada al modo de una publicidad incluida en una revista erótica. Maresca parece explicarlo con facilidad en una entrevista que le realiza Alejandra Dahla,

Tienen que ver con la libertad expresiva. Si aceptás un cierto tipo de reglas enmarcadas en el buen gusto (determinado, por otra parte, de modo arbitrario) darás por resultado los productos que configuran el arte oficial, el que la mayoría de la gente acepta gustosa porque le muestra el mundo del color rosa que quiere ver. Por ejemplo, es posible que alguien prefiera una Venus ateniense esculpida en mármol a una pieza como las mías, construidas con desechos, -cartón, madera, hierros y material descartado-. Pero acá los escultores no tenemos acceso a esos materiales costosos para trabajar y sí tenemos, en cambio, basura, elementos de desecho y un mínimo margen para transformarlos en otra cosa que muestre la realidad. Porque cuando el arte sale de su contexto deja de hacer evidente lo real y deja de cumplir, por consiguiente, con la función de modificarlo.

En esta cita Maresca pone en juego cuestiones importantes en su producción. En primer lugar establece una relación, que atravesará toda su obra, con los conceptos tradicionales de belleza y con el gusto como algo regulado desde afuera. En segundo lugar nos permite observar cierto afán de trabajar desde lo personal pero también desde lo local más allá de los gustos impuestos desde el exterior. La frase final establece claramente una mirada ética de la función de la artista y de la obra de arte.

¿Cómo pensar el corpus de obras que hemos elegido desde un abordaje centrado desde la belleza? Es imposible e irrelevante, ya que un análisis semejante no nos permite comprender la riqueza significativa de una obra como Espacio disponible que provoca en el espectador una profunda reflexión acerca de temas complejos. Teniendo en cuenta esa entrevista es evidente que lo único que le interesa a Maresca, es hablar de algo que la angustia y conmueve para poder conmover al otro, el arte debe modificar la realidad, cambiarla, mostrarla, exhibirla para producir en el espectador una nueva interpretación o comprensión de las cosas. Ateniéndonos a esa frase el problema del encasillamiento de su obra como obra de arte o no, o como cualquier otra cosa parecería ser algo que nos preocupa hoy a nosotros pero no a ella en ese momento. No podemos dejar de pensar que la necesidad de definir compartimientos en los cuales colocar las cosas tiene que ver con un esquema de comprensión que es siempre posterior a la creación misma de esas cosas, pero también con un sistema de mercado que necesita mostrarlas de modo ordenado para poder clasificarlas, darles un valor y finalmente comercializarlas en un sistema puramente económico. Es incuestionable que la gran pregunta acerca de lo que es el arte hoy en día preocupa más al mercado del arte que a muchos artistas en el momento de creación de la obra.

En el texto que acompaña la muestra Espacio Disponible, Fabián Lebanglik plantea acerca de Maresca que, 
La artista no cree más que en el arte -como trabajo, idea, imagen, conocimiento y reflexión-y a partir del arte recompone las relaciones con el mundo, en un proceso de convicción -y fe- escalonado. Es decir, Liliana Maresca no cree en nada salvo en el arte -su única certeza-, que es una inflexión; y desde ese lugar cree brutalmente y a toda costa.

Es interesante tratar de entender de qué manera esta frase de Maresca puede vincularse con la anterior o si es que podemos encontrar alguna contradicción en estas dos afirmaciones. Quizá podemos pensar que lo que plantea Maresca es un modo propio de pensar el arte, una nueva obra que esté totalmente atravesada por la intensión de comunicar una potente idea del mundo, o como ella misma lo expone citada por Gisela Rota, "Yo creo que mi misión en la vida es molestar. Hacer cosas que sean una patada en los huevos" (p. 27). Una concepción muy socrática de la función del artista que se piensa no para agradar a nadie sino para obligar a una profunda reflexión, sobre temas que quizá no gustan y que muchas veces duelen.

Y siguiendo su idea de que la obra es la que debe hablar con el espectador es que nos parece apropiado pensar la obra como discurso, entender a Maresca como el locutor de este y a su público que participa, que la interpela y responde, llama por teléfono o no lo hace, como el alocutario.

Según Emile Benveniste, el discurso es un objeto desde el cual el sujeto habla del mundo, el sujeto produce discursos y este discurso es la propia lengua en uso. Benveniste nos propone dejar de lado el concepto de Saussure de habla y reemplazarlo por el concepto de enunciación para poder comprender las relaciones que existen entre discurso e ideología y entre discurso y poder. El sujeto a través de un acto histórico, único, ubicado en el espacio /tiempo e irrepetible se apropia de la lengua y la pone a funcionar para producir un enunciado, que es la relación entre el sujeto y esa lengua. Benveniste trabaja con el concepto de enunciación, que se definiría como el acto histórico, único e irrepetible desde el cual el sujeto se apropia de la lengua y se la pone a funcionar. Enunciación es el decir, es el acto de producir un enunciado y no el texto en sí, es el acto individual de utilización de la lengua. El enunciado es lo dicho.

Es desde este lugar desde donde la obra de Maresca alcanza todo su espesor de sentido. Desde un lugar y un momento que claramente determinan la obra, Maresca se apropia de un modo de construir sentido uniendo la palabra con la imagen en una construcción única y personal.

Esa búsqueda de una obra que "hable" que menciona Maresca implica definir una situación enunciativa y un enunciado, en el que el sujeto aparece cómo problema ya que enfrenta la pregunta de su relación con el discurso.

El hombre se convierte en sujeto en la medida en que puede auto nombrarse y esto tiene muchas consecuencias. En la obra Espacio disponible Maresca se inscribe en la obra desde el texto de una forma difusa y poco reconocible. Aparece su nombre citado en el cartel que se apoya en el suelo sin ninguna otra referencia. El espacio de exposición del Casal de Catalunya es un lugar pequeño que da cita a la comunidad artística más cercana, es un lugar en el que se reúnen amigos que no necesitan mayores datos para reconocer la pertenencia de la obra. Por el contrario en Maresca se entrega todo destino, el público se amplía tanto 
que resulta ser impredecible, la revista llega a mucha gente de características imposibles de definir. El texto que acompaña esta obra no sólo incorpora el nombre sino que aparece la mención de que Liliana Maresca es escultora, la autora define desde el texto el lugar desde el que enuncia. Esa definición podría pensarse en contradicción con la imagen de las fotos que nos muestra a Maresca sin ninguno de los atributos que nos permiten reconocer el oficio del escultor, sino posando semi desnuda de manera provocativa y el único objeto que posee es un oso de peluche con el que juega cual Lolita, en una construcción totalmente estereotipada de la seducción femenina.

Es interesante pensar las 14 imágenes que aparecen en la obra Maresca se entrega... como un sistema en el que cada parte se define en relación al resto del sistema, un signo se define en relación al otro y funcionan en relación al todo. Cada una de las fotos por separado muta o pierde su sentido, generan interés cuando están todas juntas, acompañadas del texto que funciona como el elemento aglutinador que permite contextualizar y dar sentido a las imágenes. No son partes que puedan separarse sin transformarse completamente en otra cosa. Por otro lado no podemos dejar de pensar que las fotos ampliadas y enmarcadas si colgaran de la pared de una galería cada una por separado nos llevarían a realizar asociaciones totalmente diferentes. La lectura de la obra funciona como un sistema que tenemos que apreciar de manera completa.

La Referencialidad contextual, se refiere a la posibilidad de establecer el contexto que aporta el dato que permite la comprensión de una obra. Una obra si es vista en una galería esta contextualizada de una manera en particular y va a ser leída de esa manera, que será completamente diferente a una obra que está dentro de una revista erótica, por más que mencione o dé datos que permitan vincularla con el medio artístico (ya que menciona que Liliana Maresca es escultora, da los créditos de la producción, etc.) pese a todo eso es leída como publicación erótica y muchos lectores llaman sin intuir que puede haber otro sentido. Es interesante poder experimentar concreta y prácticamente de qué modo el contexto condiciona la lectura de la obra. Esto que puede aparecer como una simple intuición en otros casos se nos revela de manera concreta en la comparación de la respuesta que la artista obtuvo con las dos obras, frente a una de ella (Espacio disponible) nadie se sintió inclinado a llamar y frente a la otra la artista recibió gran cantidad de llamados.

Maresca se coloca aquí como una artista reflexiva pero pragmática, ella siempre buscó separarse de la teorización excesiva en relación al quehacer artístico. En 1991 va a participar de una muestra colectiva de esculturas en el patio de la facultad de Filosofía y Letras de la Universidad de Buenos Aires. La obra que realiza se titula Ouroboros y representa a una serpiente gigante que se come su propia cola totalmente construida de hojas de libros y apuntes, muchos de estos textos eran bibliografía de las materias que se dictaban en la facultad. El mensaje es claro y los alumnos lo entienden rápidamente y por eso el fuerte rechazo que en algunos provocó la obra. La teoría o el exceso de esta es un ejercicio que se alimenta a sí mismo y no tiene relación con el afuera, con la vida, se encuentra aislado en una universidad que lee la vida en vez de verla o vivirla. Maresca en cambio es una artista con una formación no académica que comprende su función desde la praxis. Es por esto que busca medir de manera concreta el alcance de la obra, de qué modo impacta en el espectador, entender si es que lo moviliza, esto es lo que nos permite pensar que quizá la primer obra es parte indisociable de la segunda, no por que trabaje sobre el mismo tema 
o de una manera equivalente, sino porque Maresca se entrega... es la otra estrategia que genera ante la necesidad de dialogar con el espectador.

La definición de Pierce de signo lo sitúa como aquello que está en lugar de otra cosa. Entonces ¿Maresca en lugar de qué está? Maresca posa en lugar de la artista o de la prostituta, ambas ofreciendo un servicio que socialmente nos hemos acostumbrado a entender como diferente. Esta obra nos enfrenta a una pregunta importante: desde qué lugar puede pensarse que esta diferencia no es tan significativa y esta es quizá una de las reflexiones más interesantes que plantea la artista. ¿En qué momento Maresca puede entender que una artista y una prostituta son figuras equivalentes? La frase ya citada de la entrevista realizada por Alejandra Dahla, "Si aceptás un cierto tipo de reglas enmarcadas en el buen gusto (determinado, por otra parte, de modo arbitrario) darás por resultado los productos que configuran el arte oficial, el que la mayoría de la gente acepta gustosa porque le muestra el mundo del color rosa que quiere ver", nos permite ver como Maresca piensa que el mercado del arte y la búsqueda de que obra sea aceptada por las instituciones lleva al artista a la aceptación de reglas impuestas que desvinculan el arte con la realidad, con una finalidad significativa y es ahí cuando el artista se prostituye, prostituye sus fines y trabaja sólo por dinero.

Los deícticos son los signos indiciales que establecen el yo, el aquí, y el ahora. Cuando el locutor se apropia del aparato formal de la lengua y enuncia su posición lo hace mediante indicios específicos. El locutor fija su posición al enunciar y todo enunciado implica una toma de partido, un posicionamiento. En el caso de estas obras el posicionamiento por más que nos resulte polisémico es plenamente consciente y buscado por la artista que logra generar una obra llena de capas que interpelan al espectador y lo enfrentan con una serie amplia de problemas que pueden ser abordados con distinta complejidad.

Cuando Maresca establece el Yo se coloca con su nombre y apellido, la tipografía también ayuda a posicionar la obra y la imagen es consecuente. En un primer nivel uno ve a un Yo fuerte que se hace responsable completamente de la enunciación y de lo que esta implica. Pero en la obra Maresca se entrega..., inmediatamente ella establece el colectivo, la obra con la participación del otro y los nombra uno por uno y les permite hacerse cargo de diversos fragmentos (fotografía, vestuario, maquillaje, etc.) y si bien su imagen nos la presenta sola sabemos por el texto que atrás de cámara hay mucha más gente. El texto cita que la escultora Liliana Maresca donó su cuerpo a los artistas que la acompañan en la producción, y acá se genera una fuerte ambivalencia que no nos permite precisar si Maresca se dona a sus pares (los otros artistas y amigos) o al público desconocido que ve la publicidad. Por las dudas el público llama e intenta concertar la ansiada cita.

El sujeto de la enunciación es la causa y el efecto del enunciado. El Yo que se instala desde el propio cartel que en grandes letras negras dice su nombre, será reconocido por muchos de los espectadores como el yo de la artista que hace una obra de arte. Maresca hace sus obras en primera persona, su voz y su nombre aparecen claramente como centros de la enunciación y como la razón misma de que esta suceda. Maresca está claramente inscripta en el enunciado.

Todo enunciado lleva a cabo una acción. Oswald Ducrot plantea que hablar es actuar porque lo que se busca es influir en el otro. Hablar es intervenir en una situación contextual específica. Hablar implica, compromete, construye un vínculo con el otro, busca modifi- 
car al otro. Maresca ha establecido claramente que busca molestar, pinchar al otro con la intensión de producir algún tipo de reacción, y en sus entrevistas esta parece ser la única preocupación que la mueve.

En la obra Maresca se entrega... podemos ver también a una artista que busca seducir, agradar, provocar deseo. En uno o en otro caso el tú, el alocutario, el otro de la obra no permanece indiferente y si esto sucede significa que la obra no esta funcionando y se puede volver a intentar, realizándola de alguna otra manera, buscando otra estrategia que genere que el otro llame, que el otro accione.

El enunciado construye el YO/TU y el vínculo entre los dos, Maresca busca influir en el otro y provocar una reacción, estas obras no son estéticas ni estáticas y no promueven un espectador contemplativo, la reflexión es crítica y esa crítica que producen desde el discurso debe ser sostenida por el espectador que es un participante. En el caso de Espacio Disponible la misma distribución de la obra en el espacio implica un espectador que es participativo, que recorre y trata de reconocer cuál es la obra. Benveniste plantea que hablar es llevar al otro a que saque una conclusión, no hablo sólo porque sí, o por el placer de hacerlo, hablo con una finalidad que es persuasiva.

El sujeto de la enunciación al enunciar su mensaje construye una puesta en escena de lo real que da sentido a su discurso y funciona como una contextualización de este. Tomar la palabra, decir es una puesta en escena. El enunciado es una puesta en escena, una representación de la escena de lo real.

El Ethos del enunciador tiene que ver con su presentación pública e histórica, no indica lo que es sino lo que parece, el modo en que lo hace debe resultar verosímil con el fin de generar un efecto persuasivo. Dominique Maingueneau resalta la concepción aristotélica que se plantea en la Retórica,

... la prueba mediante el ethos consiste en lograr una buena impresión a partir de la forma en que uno construye sus discurso, en dar una imagen en sí capaz de convencer al auditorio ganando su confianza... Este ethos está ligado a la enunciación misma, y no a un saber extradiscursivo sobre el hablante (p. 205).

Aristóteles entiende el discurso como una acción tendiente a una finalidad, que no sucede en el vacío, mi discurso está dirigido a convencer al otro, se ajusta a esa necesidad y funciona en consecuencia buscando estrategias para realizarla. Para Aristóteles esta finalidad es dar una buena impresión, los sofistas lo entenderán como convencer, Maresca busca movilizar y generar una impresión en el espectador aunque no sea positiva. La última parte de la cita es muy significativa por que plantea que la construcción del ethos está ligada al momento del discurso y puede prescindir de todo conocimiento anterior sobre quién enuncia. El lector de la revista El libertino, no necesariamente conoce a Maresca (ni como artista ni como prostituta) pero construye una imagen de ella con la información que obtiene en ese momento, de ese primer y único contacto.

Maingueneau explica que su noción de ethos permite articular cuerpo y discurso. La noción de ethos que propone es interesante para el análisis de esta obra ya que permite esta articulación en la que plantea que el discurso es indisociable de un cuerpo enunciante históricamente especificado. Maresca construye una obra en la que está siempre articula- 
do su discurso al cuerpo que lo enuncia, ella siempre aparece y habla en primera persona, asumiendo la responsabilidad de la enunciación de manera completa.

El Ethos se juega en el estereotipo. Simone de Beauvoir nos dice que "la mujer se hace, no nace", igual que la puta y la artista, estas se construyen con una puesta en escena que permite su rápida identificación y es por esto que su actuar es estereotipado.

En la primer obra Maresca se presenta en escena con el ethos de una artista y sostiene su discurso desde ese lugar de enunciación. Las fotos de la inauguración la muestran sonriente, posando y brindando con cada uno de los amigos y artistas que se acercó a compartir el momento.

Maresca se entrega... necesita para funcionar la construcción de un ethos diferente que instale su propio sistema de verosimilitud y juegue con la sospecha o la certidumbre de lo que estamos viendo. En estas dos obras hay una puesta en escena que es mucho más estereotipada en la construcción de una puta que en la construcción de una artista. La puta funciona para el otro no para sí misma por lo que debe ser rápidamente reconocida por ese otro a quien se dirige. Maresca utiliza el cliché de sensualidad y erotismo más artificial y estereotipado posando con un osito en una mezcla de niña mujer. Mostrando y ocultando su cuerpo al mismo tiempo como estrategia para incitar el deseo. La construcción del ethos refuerza el sentido de la oferta, la artista está disponible, se ofrece todo destino. El ethos se construye en la interacción con el destinatario.

Michel Foucault en su Lección Inaugural en el College de France plantea como hipótesis de su trabajo un abordaje político e ideológico en el uso del discurso que se nos muestra como una estrategia de poder. Foucault plantea lo siguiente:

Yo supongo que en toda sociedad la producción de discurso está a la vez controlada, seleccionada, y redistribuida por un cierto número de procedimientos que tienen por función conjurar los poderes y peligros, dominar el acontecimiento aleatorio y esquivar su pesada y temible materialidad (p. 5).

Esta idea de control sobre la producción del discurso puede ser interesante si pensamos que la artista buscará recurrir a un medio de difusión ajeno a lo que tradicionalmente pensamos como dispositivo artístico: para hablar de arte y de la condición artística, Maresca deberá salir a un ámbito diferente y mostrar la obra en una publicación erótica.

La primera obra que sucede en un espacio destinado al arte y pensado para el arte licua el mensaje. Curiosamente los interesados en reflexionar acerca de la propuesta de Maresca son en primera instancia los visitantes a la muestra del Casal de Catalunya y no los lectores de El Libertino. Sobre esto podemos pensar en función de la palabra de Maresca que cuando se refiere al futuro y cómo este mirara su obra ya entiende esta asimilación que el ambiente artístico genera de todas las obras, ya sea las que cumplen los cánones establecidos y se atienen a las reglas o las que no lo hacen nunca,

Va a ser finalmente asimilado, porque si el sistema permite la existencia de algo que se escapa de él, es para inocularlo luego. Actúa como una vacuna. Esto que hoy parece delirante, no convencional, va a ser aceptado y dejará la marginalidad. Pero entonces habrá otra generación que se propondrá modificar las 
cosas y encontrará para ello nuevos canales. No puedo decir que carecemos de nihilismo. Leer el diario enfrenta con una actualidad que no ofrece otras alternativas. Pero existe además otra tendencia en nuestro arte, que es la exaltación de la sexualidad -que algunos interpretan equivocadamente como pornografía- y eso no es nihilista en absoluto. Más bien es un grito de vida, o sea que en lo nuestro se combinan los opuestos [...].

Ese control de la palabra está dado por los procesos de exclusión y de prohibición y uno de los principios más fuertes es la sexualidad y la política, el deseo y el poder. Referirse a la violencia sobre el cuerpo femenino y el cuerpo de la artista desde su puesta en escena, tomar el poder de la palabra y del propio cuerpo transformándolo en objeto de deseo, es un acto político de reafirmación del poder.

\section{Conclusión o cierre}

Explorar la posibilidad de analizar la obra como si fuera un texto, si bien no transforma la obra, ni muta sus sentidos si nos permite elaborar una compresión más profunda de las diversas capas interpretativas que presentan. La obra interpela al espectador desde la distancia en el tiempo y sigue provocando una serie de preguntas que el espectador debe encontrar el modo de responder. Ampliar los marcos teóricos de trabajo es un modo de relacionarnos con una obra profundamente compleja y rica.

Esto implica ampliar los modos de reflexión sobre una artista que se abre múltiple ante nosotros, en uno de sus poemas publicados en El amor - lo sagrado - el arte, ella misma plantea todo lo que la conforma, lo bueno y lo malo, todo lo que ha vivido es ella y podríamos agregar su obra.

El sida es una de las cosas que me pasan

Que pasa por mí

Me da especificidad

Soy lo que soy ahora

También porque tengo sida

Soy esto

Una guerrera sedienta

\section{Bibliografía}

AAVV (2016). Catálogo, Liliana Maresca. Museo de Arte Moderno de Buenos Aires.

Benveniste, E. (1995). Problemas de lingüística general II. México: Siglo XXI.

Butler, J. (1990). Actos performativos y constitución del género: un ensayo sobre fenomenología y teoría feminista. En Sue-Ellen Case (comp), Performing Feminims: Feminist Critical Theory and Theatre, Johns Hopkins University Press. 
Cuellar, C. (2002). Nuevo sexo y nueva carne. Erotismo, pornografía y nueva carne. En La nueva carne. Una estética perversa del cuerpo. España: Valdemar.

Dahla, A. (1987). "Una escultura underground desgrana el espíritu punk" en diario La Razón, Buenos Aires, lunes 12 de enero.

Ducrot, O. (2001). El decir y lo dicho. Buenos Aires: Edicial.

Foucault, M. (1992). El orden del discurso. Buenos Aires: Letra e.

Maingueneau, D. (2010). El enunciador encarnado. La problemática del ethos. México: UAM-X.

Maresca, L. (2006). El amor - lo sagrado - el arte. Buenos Aires: Ed. Leviatán, Colección El viaje. Sánchez, J. "Una artista se ofreció 'para todo destino' en una revista erótica” en revista $L a$ Maga, $\mathrm{N}^{\circ}$ 99, Buenos Aires, 8 de diciembre.

Rota, G. (1991). "Liliana Maresca: el placer de romper libros", en Cerdos y peces, $\mathrm{N}^{\circ} 42$, Buenos Aires, septiembre.

\begin{abstract}
This text think about two works of the Argentinian artist Liliana Maresca: called "Available space" and "Maresca offers all destinations" and tries to establish the lines that connect the two samples. It will also observe how complementary are each other and to establish a dialogue with the viewer generating own reflection and suggest another. The two chosen works will be designed from theoretical frameworks of semiology and the analysis of the discourse in order to cover their complexity. It enquires also about the role of the artist in the local environment, the use of the body and its staging and the links that the artist kept with institutions and the market.
\end{abstract}

Keywords: Liliana Maresca - Contemporary Art - Semiotics - Body - Photography.

Resumo: Este texto reflete sobre duas obras da artista argentina Liliana Maresca: Espaço disponivel e Maresca oferece todo o destino, tentando estabelecer as linhas que unem as duas amostras, e observar como se complementam para atingir um objetivo que podemos traçar em praticamente todas as suas obras : estabelecer um diálogo com o espectador e influenciar sua vida de alguma forma, gerar sua própria reflexão e fazer o outro pensar. Os dois trabalhos escolhidos serão pensados a partir de referenciais teóricos de semiologia e análise do discurso, a fim de abranger a complexidade que ambos propõem na investigação sobre o papel do artista no ambiente local, o uso do corpo e sua encenação, e links que o artista mantém com as instituições e o mercado. Basearemos este trabalho nas informações obtidas em entrevistas, a fim de podermos dar conta da palavra do artista que foi gravada e gravada por diferentes pessoas durante o curso de sua carreira.

Palavras chave: Liliana Maresca - Arte Contemporânea - Semiologia - Corpo - Análise do discurso - Fotografia - Arte Argentina.

[Las traducciones de los abstracts fueron supervisadas por el autor de cada artículo] 